\title{
Raiva em equino no município de Porto Alegre - RS, Brasil
}

\author{
Equine rabies in the city of Porto Alegre - RS, Brazil \\ Luciana Paula Merini', Alexandra Tiso Cormelato ${ }^{2}$, Carlos Afonso de Castro Beck ${ }^{3}$, Petra Garbade ${ }^{3}$, \\ Flávia Umpierre Bueno ${ }^{4}$, Pedro Miguel Ocampos Pedroso ${ }^{5}$ \& Samuel Carnesella ${ }^{2}$
}

\begin{abstract}
Background: rabies is a fatal zoonosis caused by a highly neurotropic RNA virus which causes neurological signs and that is distributed almost worldwide. Rabies affects domestic and wild animals and this is a disease transmitted by their bites, through which the virus present in the saliva is inoculated. In Brazil, Desmodus rotundus is the main hematophagous bat species that transmits rabies, especially to herbivores e equines. In equines, the clinical manifestation varies a lot, including both the paralytic and the furious form of the disease. The goal of this study is to describe a case of equine rabies in the city of Porto Alegre, Rio Grande do Sul, Brazil.

Case: a six-year old male American Quarter Horse, which presented a clinical picture characterized by colic, depraved appetite and difficulty to move, was admitted to the Hospital de Clínicas Veterinárias of Universidade Federal do Rio Grande do Sul (HCV-UFRGS). The horse did not respond to treatment, therefore, it was submitted to exploratory laparotomy, when the moderate intestinal constipation and low intestinal motility was observed. A large colon enterotomy was performed and the intestinal contents were partially emptied. During recovery from anesthesia, the animal remained in lateral decubitus, not making any attempt to stand up. The animal did not show a favorable clinical evolution a few hours later, displaying weakness particularly in the hind limbs. Consequently, the animal underwent euthanasia. Samples of body organs were collected and fixed in formol $10 \%$, processed routinely for histological purposes and then stained by hematoxylin and eosin. The histopathological examination revealed nonsuppurative meningoencephalitis in the central nervous system, without the presence of Negri bodies. Due to the history of recent rabies cases in neighbor areas of the property from where the animal came, direct immunofluorescence (IFD) and immunohistochemical (IHQ) exams for rabies were requested. The result was negative in IFD and a positive immunolabeling was observed in IHQ, thus demonstrating a viral antigen labeling in neurons of the cervical spine, pons, mesencephalon and cerebellum.

Discussion: intracytoplasmic inclusions, also known as Negri bodies, are important and pathognomonic findings that were not observed in this case. Its presence and concentration depend on the stage and course of the disease, and they are not present in up to $30 \%$ of rabies cases, because certain virus strains do not produce Negri bodies. In equines, the occurrence of Negri bodies is less frequent than in bovines. IFD is the most adequate rabies diagnosis method, which is a highly sensitive technique (80-100\%). The result was negative for this case, being confirmed only by IHQ. The immunohistochemical test is an important laboratorial diagnosis tool of rabies, because it allows the solution of unspecific meningoencephalitis cases when Negri bodies are not present. The treatment of animals with rabies is not considered. Vaccination in endemic regions or in areas where a rabies case has occurred is necessary. Rabies cases near the property where the animal lived were reported, but a prophylactic vaccination was not carried out. Rio Grande do Sul had a peculiar epidemiological status regarding rabies, as urban rabies cases had not been reported for approximately 17 years. However, rabies transmitted by hematophagous bats is still endemic in rural areas. This case demonstrates the importance of maintaining a rabies vaccination schedule in equine properties.
\end{abstract}

Keywords: central nervous system, immunohistochemistry, equine colic syndrome.

Descritores: sistema nervoso central, imuno-histoquímica, síndrome cólica equina. 


\section{INTRODUÇÃO}

A raiva é uma zoonose fatal [12,17] causada por um vírus RNA, envelopado, da ordem Mononegavirales, família Rhabdoviridae e do gênero Lyssavirus, distribuída em quase todo o mundo [9]. Na América do Sul, a raiva é transmitida por morcegos hematófagos, principalmente o Desmodus rotundus e os bovinos e equinos são as espécies mais afetadas $[8,9]$. A raiva afeta animais domésticos e silvestres, sendo transmitida a partir da inoculação do vírus contido na saliva através da mordedura [12]. Ele é altamente neurotrópico, causando sinais clínicos neurológicos [1].

Em equinos, a manifestação clínica é muito variável, incluindo tanto a forma paralítica quanto a forma furiosa da doença [6]. Nos casos de ocorrência natural, os sinais clínicos podem incluir posturas anormais, relinchos, agressividade e escoiceamentos inexplicáveis, cólicas, estabelecimento repentino de claudicação de um membro, seguida por decúbito e morte [14].

O teste de imunoflorescência direta que detecta antígenos do vírus da raiva em tecidos cerebrais é o teste de eleição para diagnosticar a raiva em animais [11]. Histologicamente, pode-se confirmar o diagnóstico através dos achados característicos e pela presença de corpúsculos de Negri [9].

O tratamento de animais com raiva não é estipulado, sendo o controle da doença feito através da vacinação [4].
O objetivo do presente trabalho é de relatar um caso de raiva em um equino no município de Porto Alegre, Rio Grande do Sul, tendo o diagnóstico confirmado pos mortem pelo exame de imunohistoquímica.

\section{RELATO DE CASO}

Foi atendido no Hospital de Clínicas Veterinárias da Universidade Federal do Rio Grande do Sul (HCV-UFRGS), um equino macho, da raça Quarto de Milha, seis anos de idade, que apresentava um quadro clínico caracterizado por dor abdominal intensa (cólica), apetite depravado e dificuldade de locomoção. Não respondendo ao tratamento, este foi encaminhado para realização de laparotomia exploratória, onde foi observada obstipação intestinal moderada e baixa motilidade intestinal. Foi realizado enterotomia do cólon maior e esvaziamento parcial do conteúdo intestinal. Durante a recuperação anestésica, o animal permaneceu em decúbito lateral sem realizar tentativas para ficar em estação (Figura 1A). Após algumas horas sem evolução clínica, o animal apresentava fraqueza, principalmente nos membros posteriores. Verificando-se que este já não mais estava sob o efeito de fármacos anestésicos e sedativos, o paciente foi eutanasiado e, posteriormente, encaminhado para realização de necropsia pelo Setor de Patologia Veterinária (SPV) da UFRGS. Amostras de órgãos foram coletadas e fixadas em formol $10 \%$, processadas de forma rotineira para histologia e coradas pela hematoxilina e eosina.

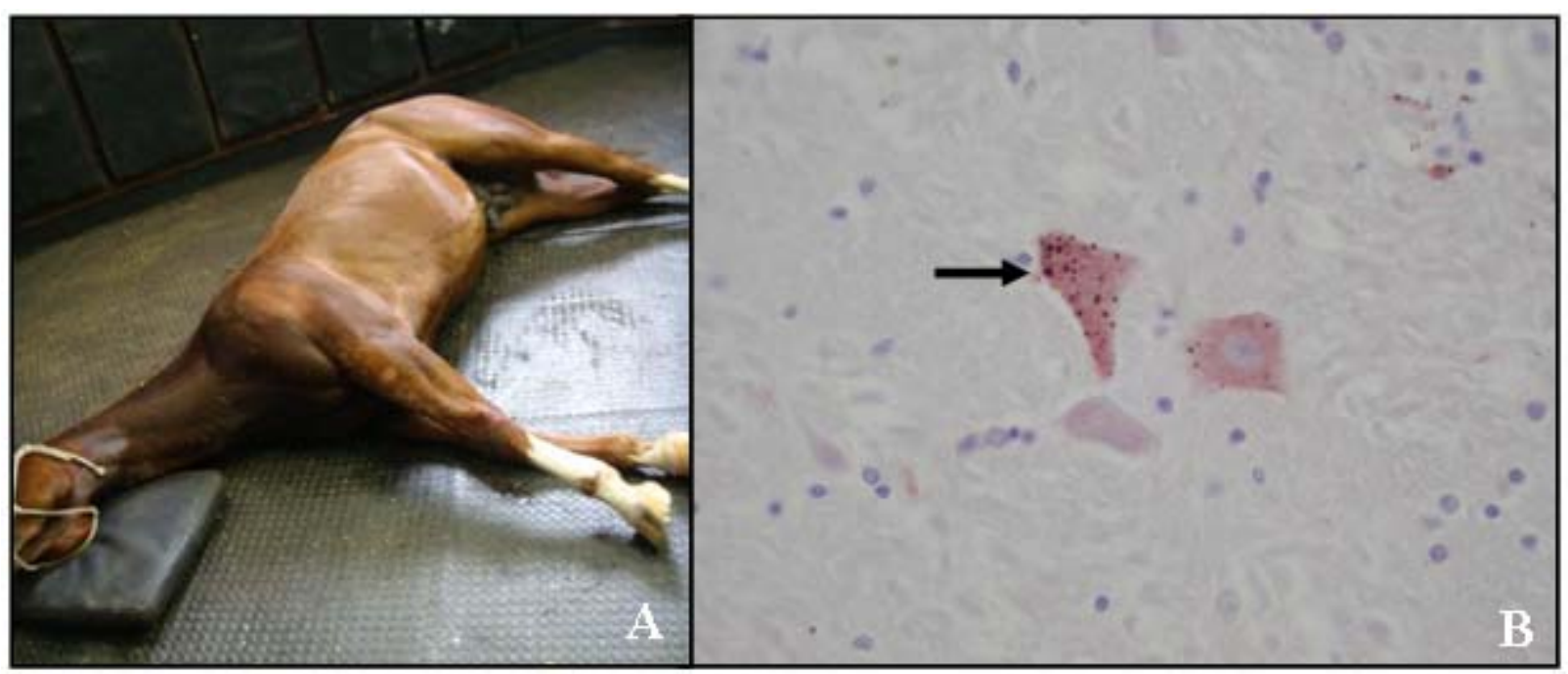

Figura 1. A. Raiva em equino. Equino em decúbito lateral direito. Fase flácida. B. Imunomarcação do antígeno da raiva. Imuno-histoquímica. Método biotina-estreptavidina-peroxidase. obj. 20x. 
Ao exame macroscópico verificou-se bexiga urinária repleta. $\mathrm{O}$ intestino apresentava a serosa e a mucosa avermelhadas com acentuada presença de muco na luz intestinal. No pulmão, verificou-se enfisema. O rim estava congesto. O fígado possuía aumento dos lóbulos laterais direito e esquerdo. Ao exame histopatológico, observou-se meningoencefalite não supurativa no sistema nervoso central, sem presença de corpúsculos de Negri.

Em decorrência do histórico de casos recentes de raiva nas áreas próximas à propriedade de procedência do animal, foi solicitado o exame de imunofluorescência direta (IFD) e imuno-histoquímica (IHQ) para Raiva. Na IFD o resultado foi negativo e na IHQ houve imunomarcação positiva, demonstrando marcação do antígeno viral em neurônios da medula espinhal cervical, ponte, mesencéfalo e cerebelo (Figura 1B).

\section{DISCUSSÃO E CONCLUSÃO}

A forma paralítica da raiva caracteriza-se por claudicação e fraqueza de um membro, mas o padrão usual de desenvolvimento começa com cansaço, passando posteriormente para decúbito esternal, e mais tarde, decúbito lateral, seguido por convulsões e morte [9]. Neste caso, as manifestações clínicas concordam com a citação acima. $\mathrm{O}$ animal apresentou também apetite depravado que caracteriza um dos sinais clínicos da fase furiosa da raiva, indo de acordo com a literatura consultada $[9,14]$.

Antes do aparecimento da forma paralítica, o animal pode deitar, rolar várias vezes, o que pode ser confundido com a síndrome cólica dos equinos [14]. Neste caso, como o animal apresentava esses sinais clínicos, foi primeiramente suspeitado de síndrome cólica e estipulado tratamento cirúrgico. Foi durante a recuperação anestésica, quando o animal apresentou decúbito e paralisia terminal, que se suspeitou de raiva e então realizada a eutanásia e encaminhado para a necropsia.

As lesões de raiva achadas na necropsia são geralmente limitadas ao sistema nervoso central [4]. Não há lesões macroscópicas de significado, porém, nesse caso a bexiga repleta significa um achado secundário resultante da paralisia do órgão [5] em consequência do envolvimento da medula espinhal na infecção pelo vírus da raiva [10].

$\mathrm{O}$ achado histopatológico de meningoencefalite não supurativa no sistema nervoso central encontrado nesse caso foi semelhante aos descritos por outros autores $[3,5,6]$. Um achado importante e patognomônico são as inclusões intracitoplas-máticas, também chamadas de corpúsculo de Negri [15], porém não foram encontradas neste caso. Sua presença e concentração dependem do estágio e curso da doença [3] e não estão presentes em até $30 \%$ dos casos de raiva, pois certas cepas do vírus não produzem corpúsculos de Negri $[4,6]$. Na espécie equina, o aparecimento de corpúsculos de Negri é menos frequente do que em bovinos [8].

A forma mais adequada de diagnóstico para a raiva é a IFD, que é uma técnica altamente sensível $(80-100 \%)[4,16]$. Neste caso, obteve-se resultado negativo, sendo confirmado somente pela IHQ.

Em um estudo, o teste de imuno-histoquímica, mostrou ser uma ferramenta importante de diagnóstico laboratorial, pois possibilita solucionar casos inespecíficos de meningoencefalite sem a presença de corpúsculos de Negri [7].

O tratamento de animais com raiva não é considerado [2]. Nos cavalos, a raiva é uma doença fatal e nenhum tratamento deve ser instituído. Faz-se necessário o uso de vacinação em regiões endêmicas ou em que tenha ocorrido algum caso de raiva [14]. Houve, perto da propriedade onde estava o animal, casos de raiva, mas não foi estipulada uma vacinação profilática.

O Rio Grande do Sul apresentava um status epidemiológico peculiar, em relação à raiva, pois não ocorriam casos de raiva urbana há aproximadamente 17 anos. Entretanto, a raiva transmitida por morcegos hematófagos ainda é endêmica no meio rural [13].

Este caso mostra o quão importante é manter um calendário de vacinação contra a raiva em propriedades criadoras de equinos. 


\section{REFERÊNCIAS}

1 Batista H.B.C.R., Franco A.C. \& Roehe P.M. 2007. Rabies: a brief review. Acta Scientiae Veterinariae. 35(2): 125-144.

2 Dierks R.E. 1981. Rabies. In: Howard J.L. Current Therapy I: Food Animal Practice. Philadelpha: W.B. Saunders Company, p. 601.

3 Fernandes C.G. 2001. Raiva. In: Riet-Correa F., Schild A.L., Méndez M.C. \& Lemos R.A.A. (Eds). Doenças de ruminantes e equinos. 2.ed. São Paulo: Varela, pp. 149-162.

4 Jones T.C., Hunt R.D. \& King N.W. 2000. Patologia veterinária. 6.ed. Barueri: Manole, p. 1415.

5 Langohr I.M., Irigoyen L.F., Lemos R.A.A. \& Barros C.S.L. 2003. Aspectos epidemiológicos, clínicos e distribuição das lesões histológicas no encéfalo de bovinos com raiva. Ciência Rural. 33(1): 125-131.

6 Lima F.S., Gomes A.A.B., Lima E.F., Riet-Correa F. \& Castro R.S. 2005. Sinais clínicos, distribuição das lesões no sistema nervoso e epidemiologia da raiva em herbívoros na região Nordeste do Brasil. Pesquisa Veterinária Brasileira. 25: 250264.

7 Pedroso P.M.O. 2008. Diagnóstico histológico e imunoistoquimico de raiva em herbívoros. 70f. Porto Alegre - RS. Dissertação (Mestrado em Ciências Veterinárias) - Programa de Pós-Graduação em Ciências Veterinárias, Universidade Federal do Rio Grande do Sul.

8 Peixoto Z.M.P., Cunha E.M.S., Sacramento D.R.V., Souza A.M.C; da Silva L.H.Q., Germano P.L., Kroeff1 S.S. \& Kotait1 I. 2000. Rabies laboratory diagnosis: peculiar features of samples from equine origin. Brazilian Journal of Microbiology. 31(1): 72-75.

9 Radostits O.M., Henderson J.A. \& Blood D.C. 2002. Clínica Veterinária. 9. ed. Rio de Janeiro: Guanabara Koogan, p.1737.

10 Sherman J. \& Schaal E. 1987. Localized deseases of the bovine brain and espinal-cord. The Veterinary Clinics of North America - Food Animal Practice. 3(1): 179-191.

11 Smith J.S. 1996. New aspects of rabies with emphasis on epidemiology, diagnosis, and prevention of the disease in the United States. Clinical Microbiology Reviews. 9(2): 166-176.

12 Summers B.A., Cummings J.F. \& Lahunta A. 1995. Veterinary neuropathology. Baltimore: Mosby, p.527.

13 Teixeira T.F., Batista H.B.C.R., Schmidt E. \& Roehe P.M. 2005. Antigenic studies on rabies virus isolates from the state of Rio Grande do Sul, Brazil. Acta Scientiae Veterinariae. 33(3): 271-275.

14 Vasconcellos L.A.S. 1995. Problemas neurológicos na clínica de eqüinos. São Paulo: Livraria Varela, p.47.

15 Zachary J.F. 2007. Nervous system. In: McGavin M.D. \& Zachary J.F. (Eds). Pathologic basis veterinary disease. 4th edn. St. Louis: Mosby, pp.833-971.

16 Zimer K., Wiegand D., Manz D., Frost J.W., Reinacher M. \& Fresc K. 1990. Evaluation of five different methods for routine diagnosis of rabies. Zentralbl Veterinarmed B. 37(5): 392-400.

17 Woldehiwet Z. 2005. Clinical laboratory advances in the detection of rabies virus. Clinica Chimica Acta. 351(1-2): $49-63$. 